Supplement of Atmos. Chem. Phys., 21, 4431-4451, 2021

https://doi.org/10.5194/acp-21-4431-2021-supplement

(C) Author(s) 2021. CC BY 4.0 License.

(c) (i)

Supplement of

\title{
10-year satellite-constrained fluxes of ammonia improve performance of chemistry transport models
}

Nikolaos Evangeliou et al.

Correspondence to: Nikolaos Evangeliou (nikolaos.evangeliou@nilu.no)

The copyright of individual parts of the supplement might differ from the article licence. 


\section{SUPPLEMENTARY FIGURES}
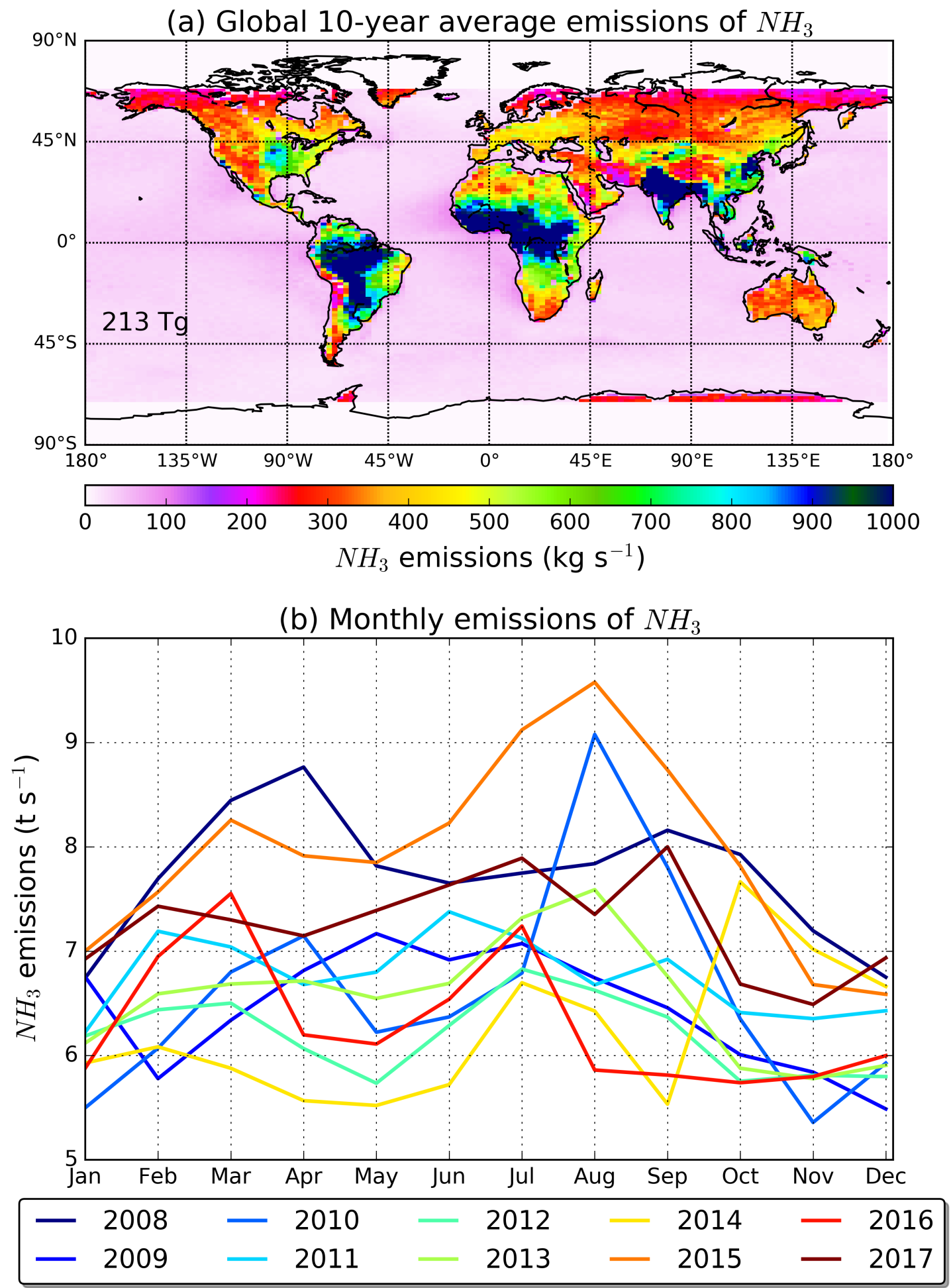

Fig. S1. (a) 10-year average emissions of ammonia (NE) constrained by IASI satellite measurements. (b) Monthly emissions of ammonia for the 2008 - 2017 period. 


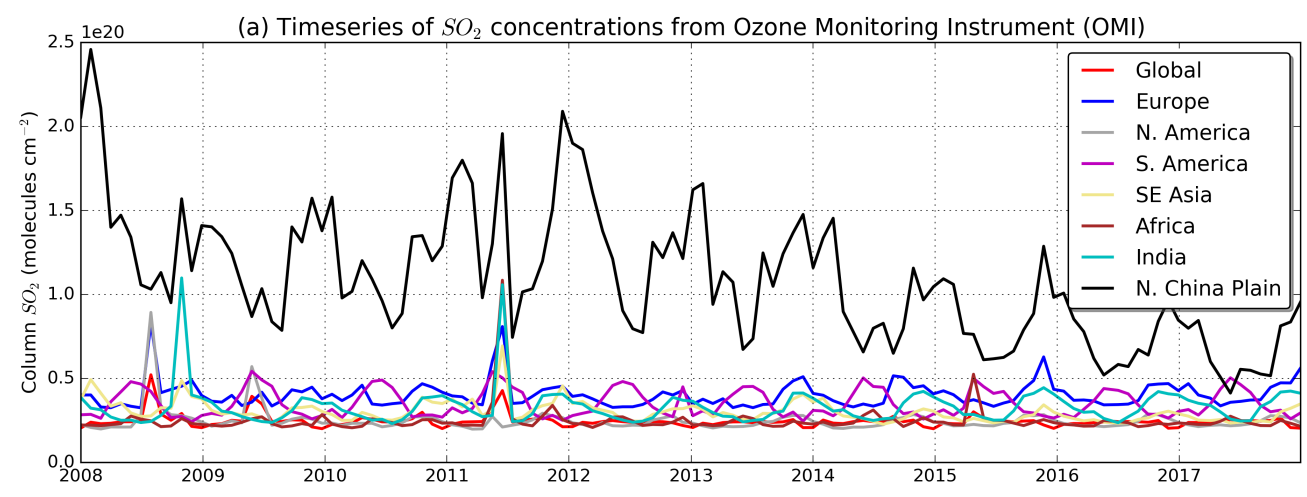

(b) Timeseries of $\mathrm{SO}_{4}$ concentrations from Modern-Era Retrospective analysis

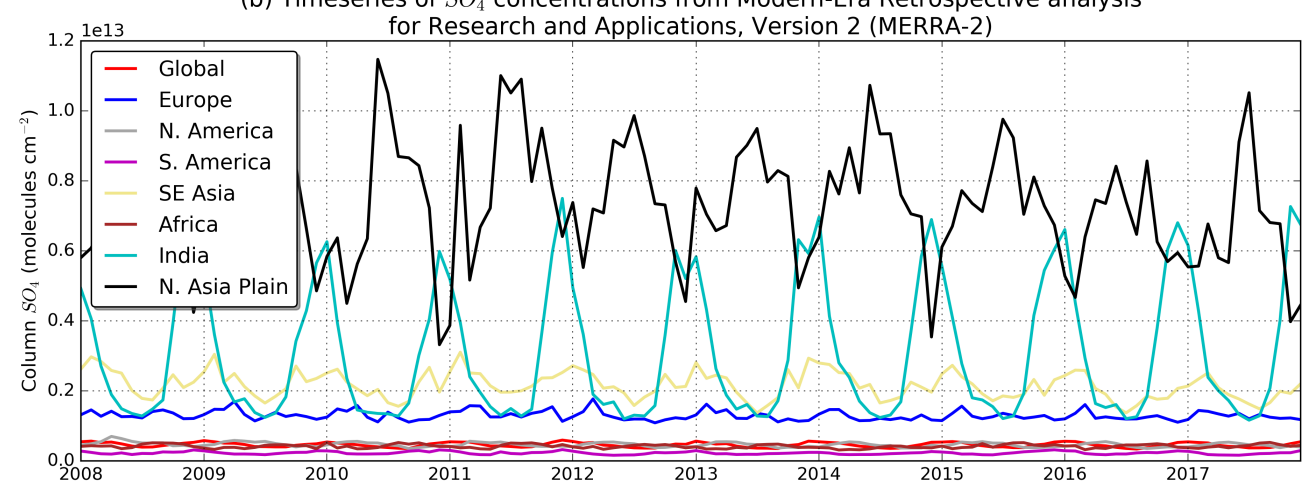

(c) Timeseries of $\mathrm{NO}_{2}$ concentrations from Ozone Monitoring Instrument (OMI)

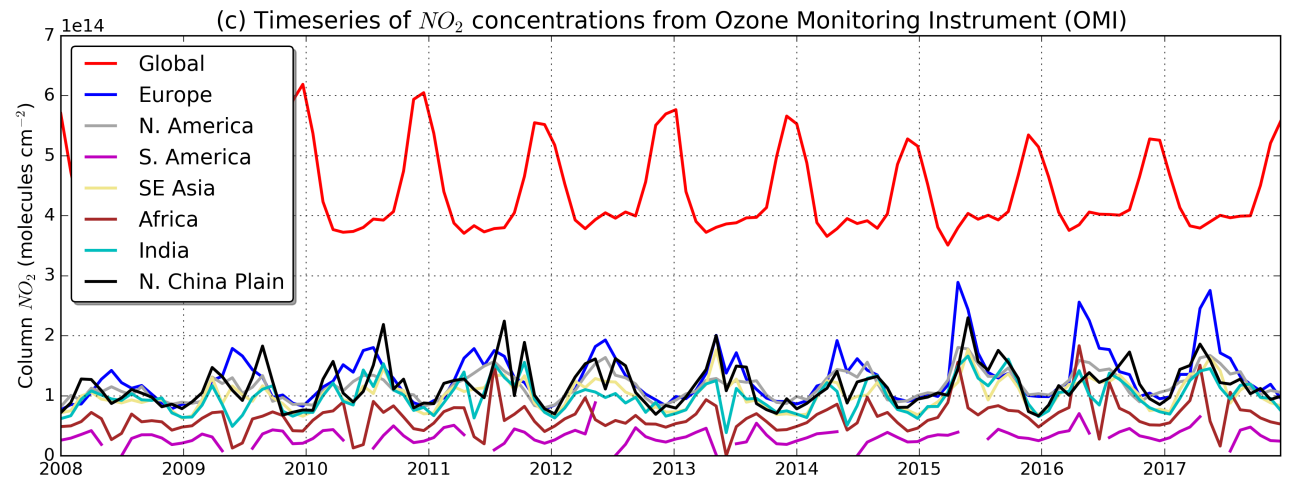

Fig. S2. Timeseries of (a) average column sulfur dioxide from OMI, (b) average column sulfates from MERRA2 and (c) nitrogen dioxide from OMI (molecules $\mathrm{cm}-2$ ) showing that the calculated emissions are due changes of the reactants of ammonia in North China Plain only. 
(a) Column $\mathrm{SO}_{4}$ anomaly after 2015 from Modern-Era Retrospective analysis
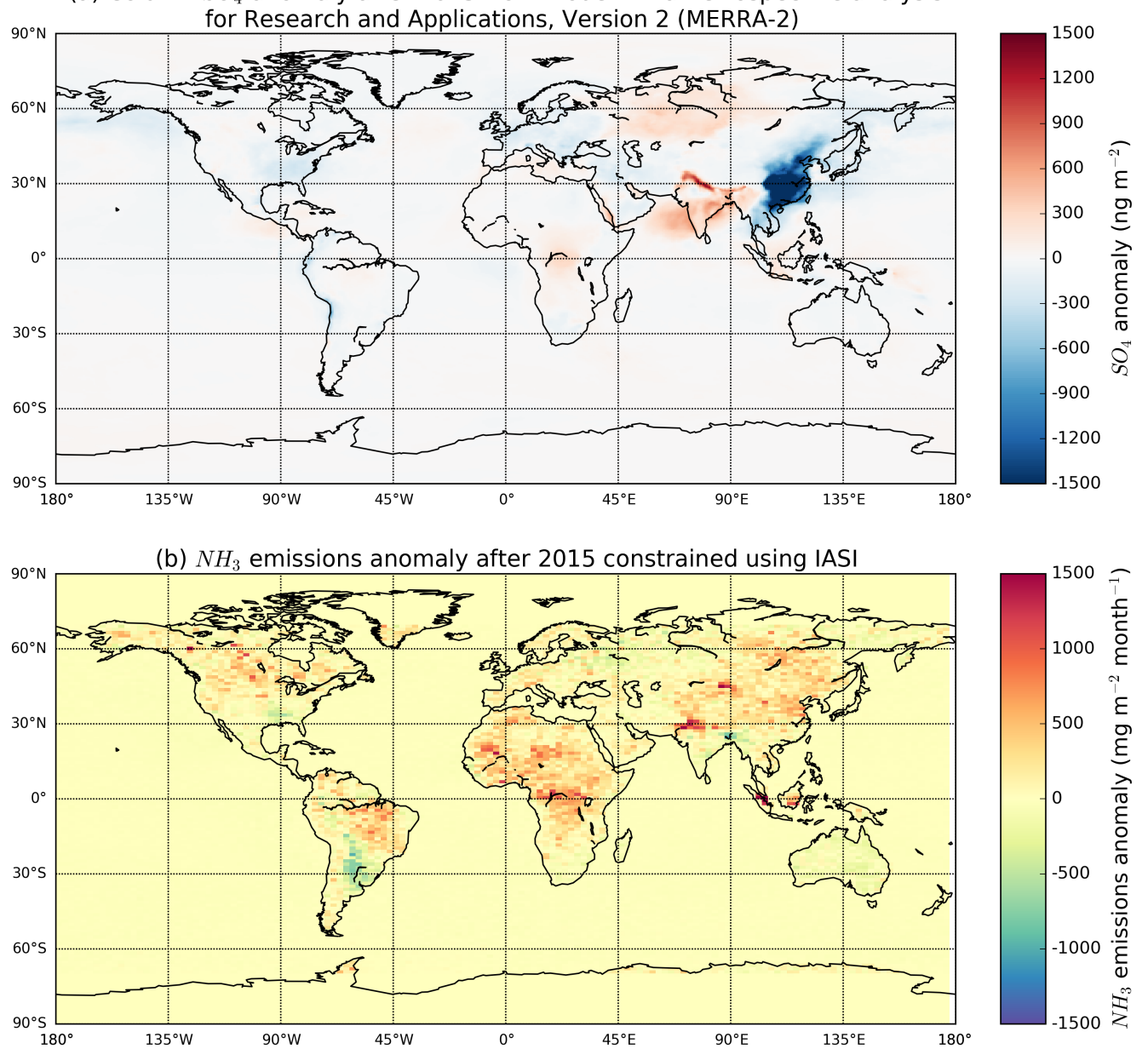

Fig. S3. (a) Annual average column sulfate anomaly after 2015 from MERRA-2, and (b) Annual average emission anomaly of ammonia emissions calculated from IASI (NE emissions). 


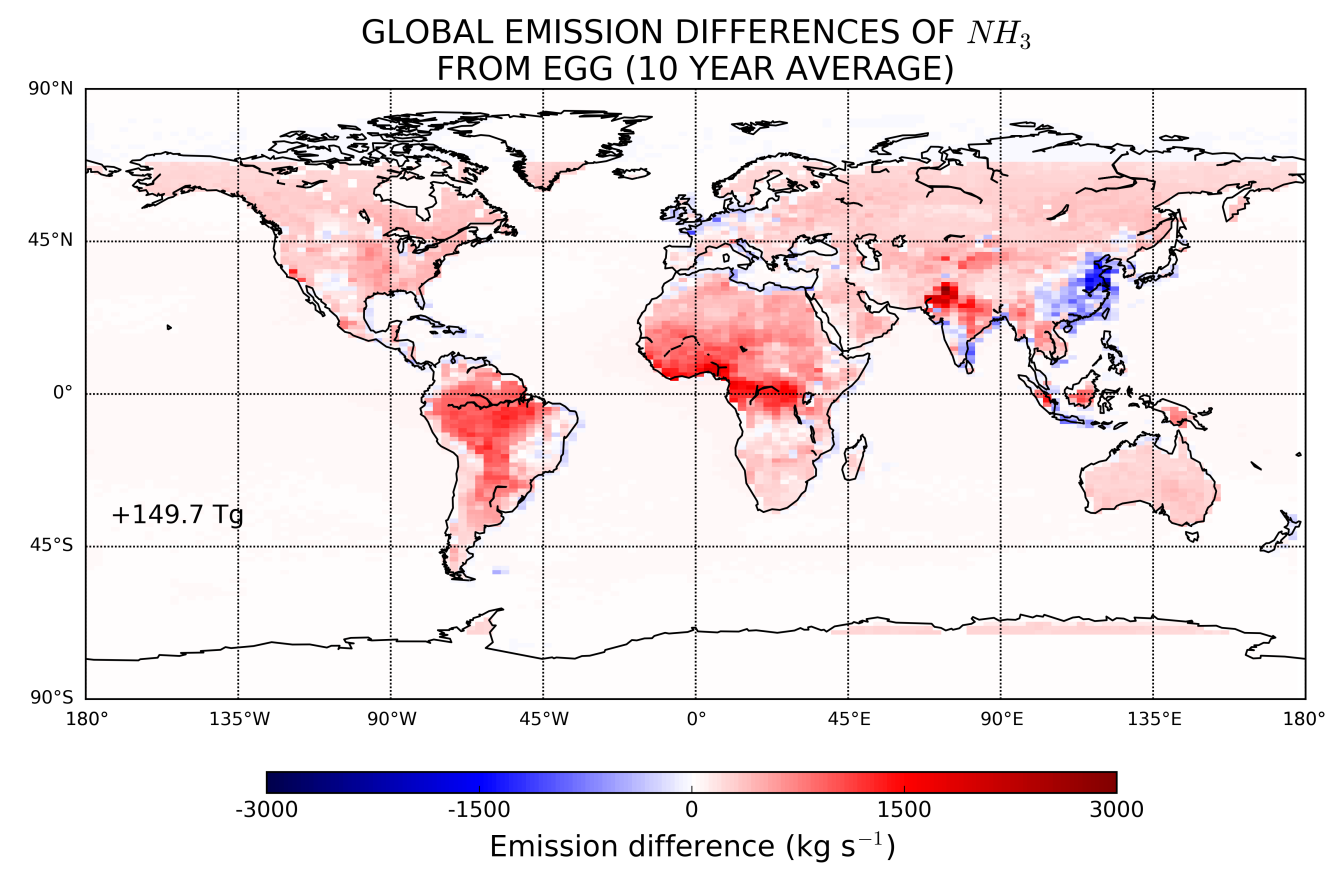

Fig. S4. Global differences of ammonia emissions calculated in the present study (NE) from ECLIPSEv5-GFED4-GEIA (EGG) (Bouwman et al., 1997; Giglio et al., 2013; Klimont et al., 2017). The results are given as 10-year average (2008-2017) and the number denotes the annual difference in the emissions. 


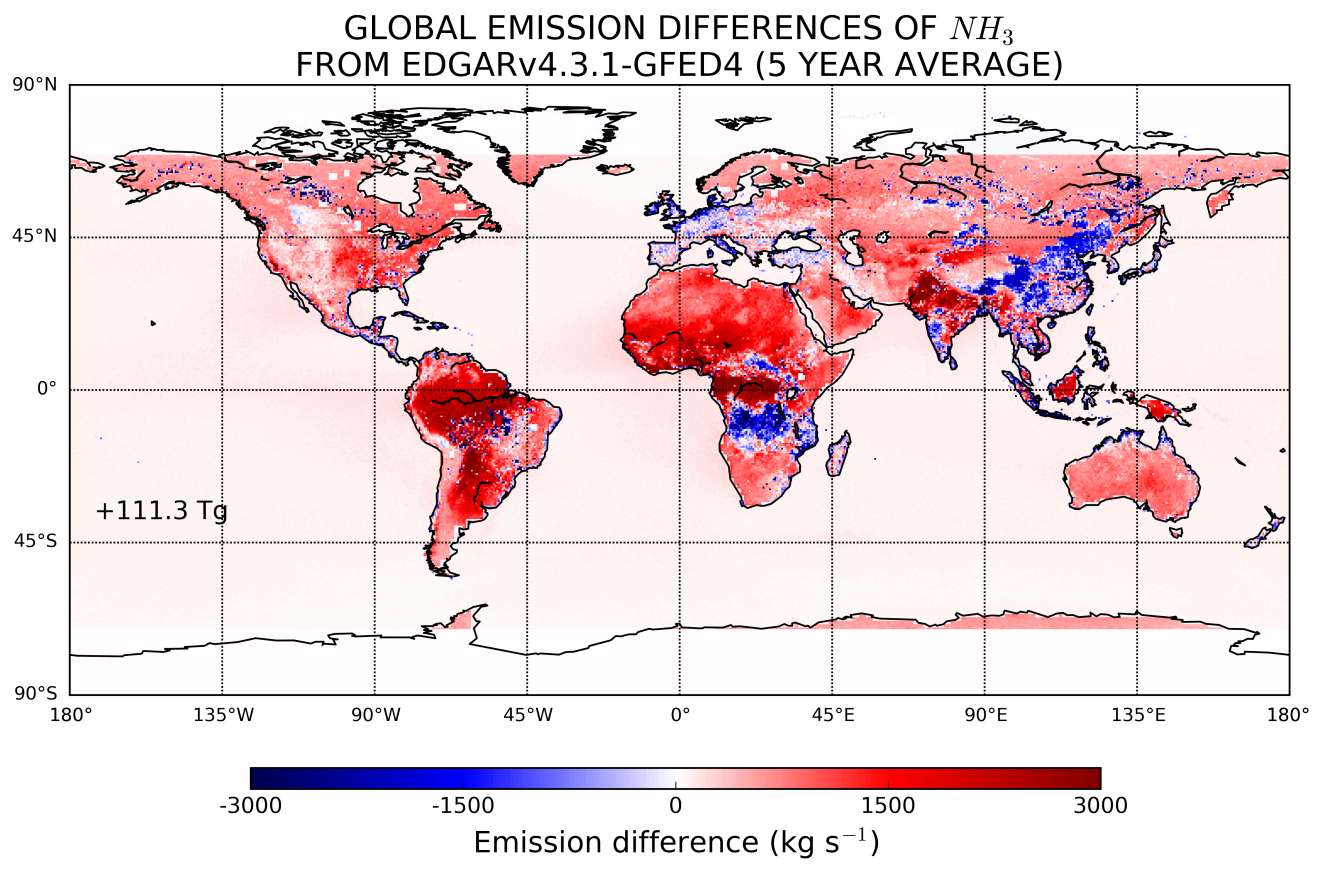

Fig. S5. Global differences of ammonia emissions calculated in the present study (NE) from EDGARv4.3.1-GFED4 (Crippa et al., 2016; Giglio et al., 2013). The results are given as 5year average (2008-2012) and the number denotes the annual difference in the emissions. 


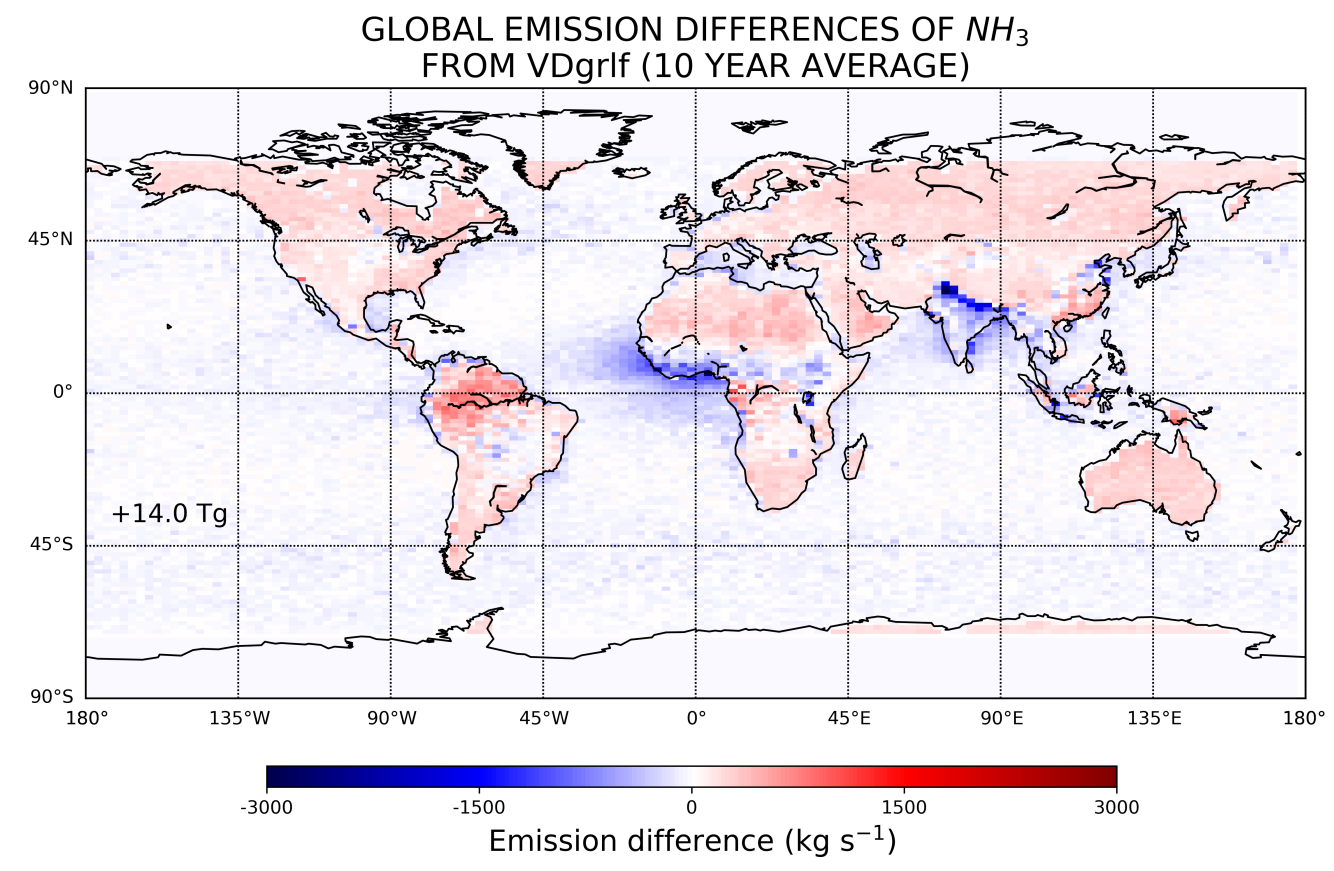

Fig. S6. Global differences of ammonia emissions calculated in the present study (NE) from those calculated using Van Damme et al. (2018) gridded concentrations applying a gridded variable lifetime from a CTM (VDgrlf). The results are given as 10-year average (2008-2017) and the number denotes the annual difference in the emissions. 

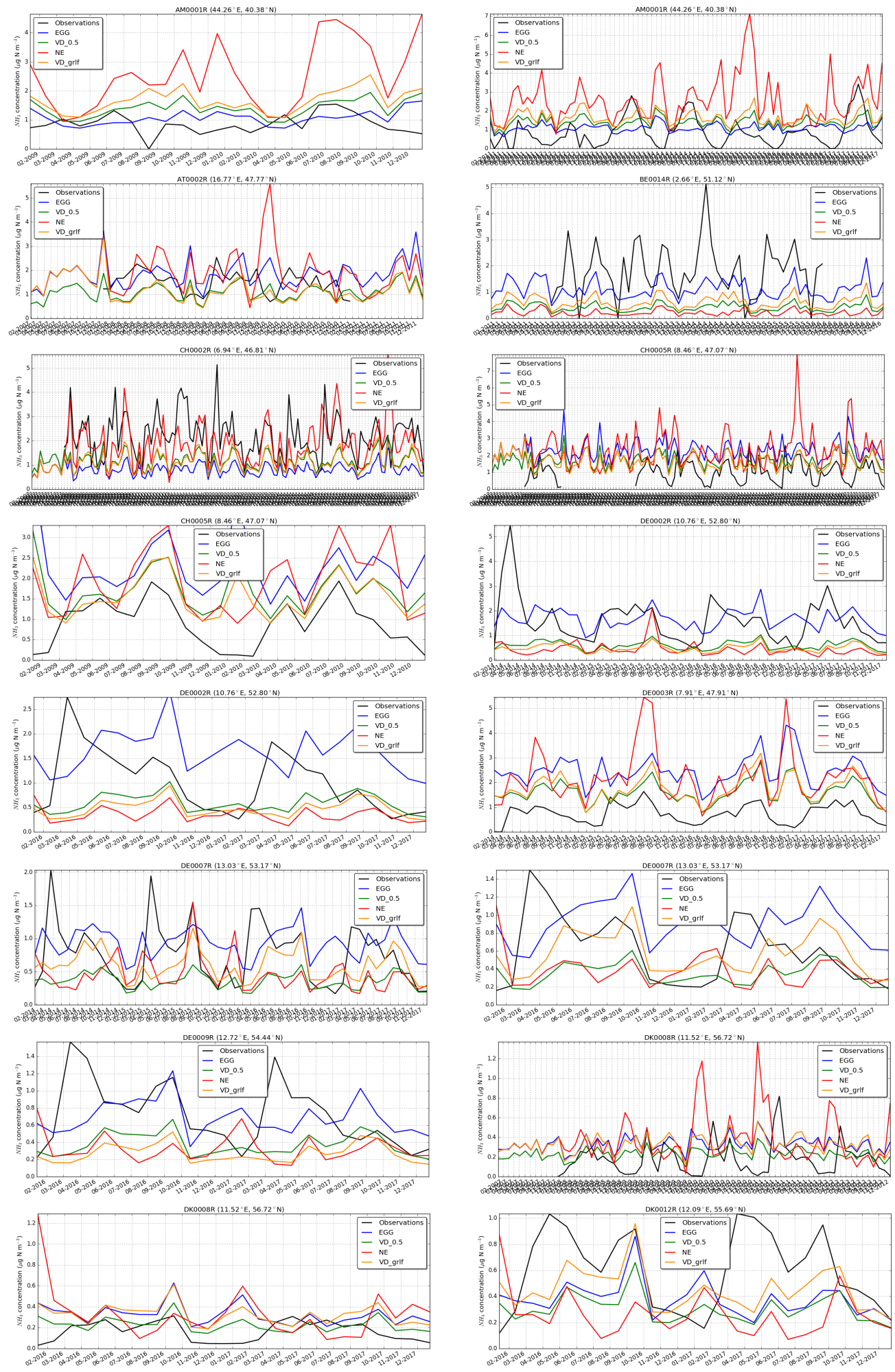

Fig. S7. Time-series of surface concentrations of ammonia in European measurement sites (EMEP) for each of the simulations with different emissions. EGG stands for the simulation using traditional emissions from ECLIPSEv5, GFED4 and GEIA datasets, VD0.5 using Van Damme et al. (2018) satellite ammonia applying a constant lifetime for ammonia of 12 hours, NE using emissions presented in this paper (see section 2), and VDgrlf shows concentrations from the simulation using Van Damme et al. (2018) satellite ammonia applying a variable (modelled) lifetime. 


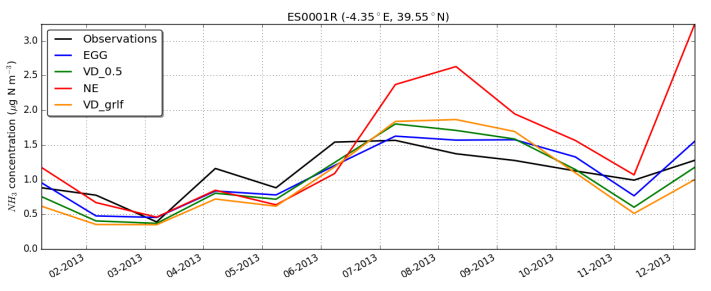

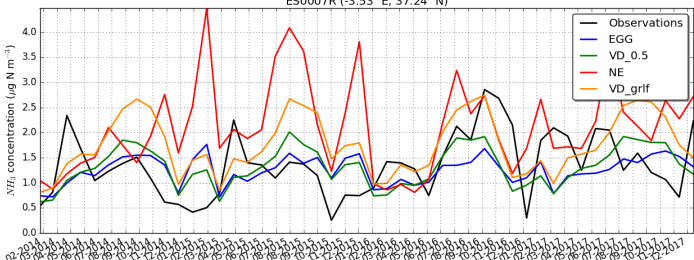
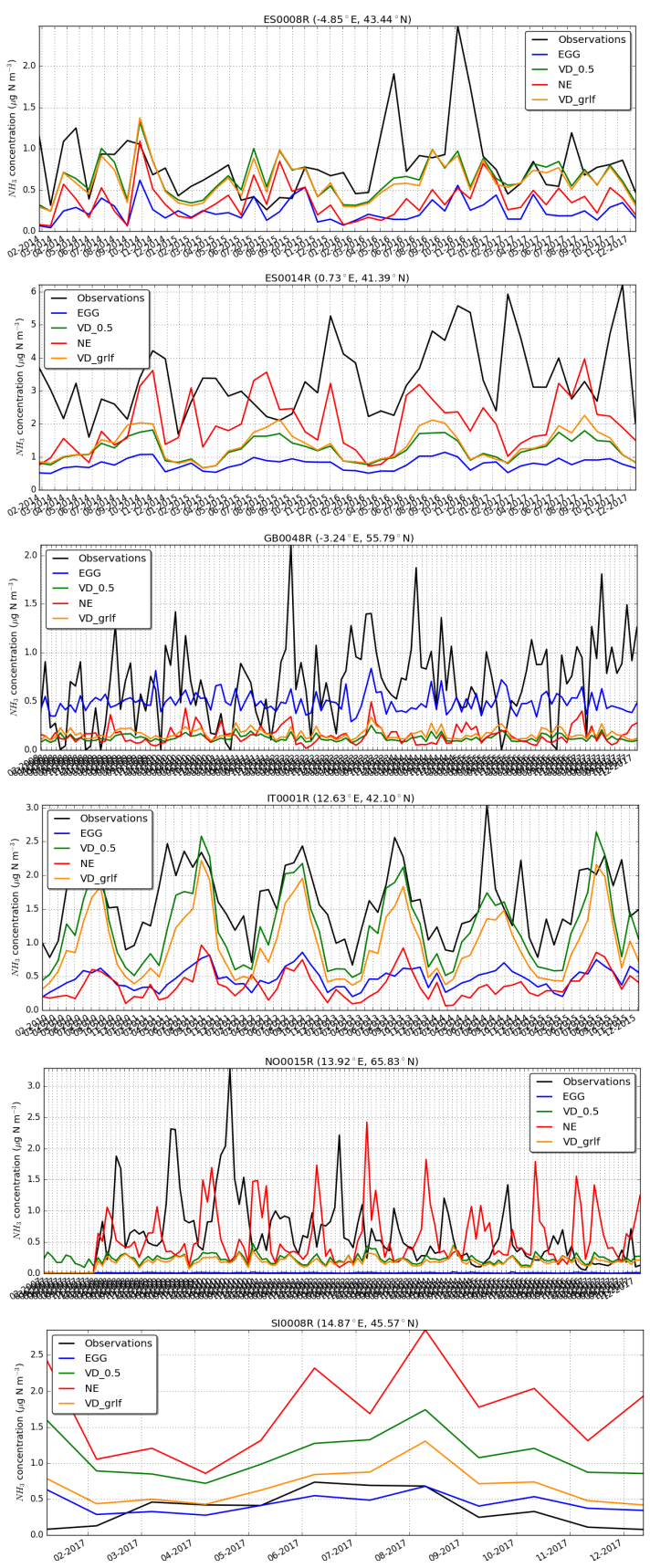

Fig. S7. Continued.
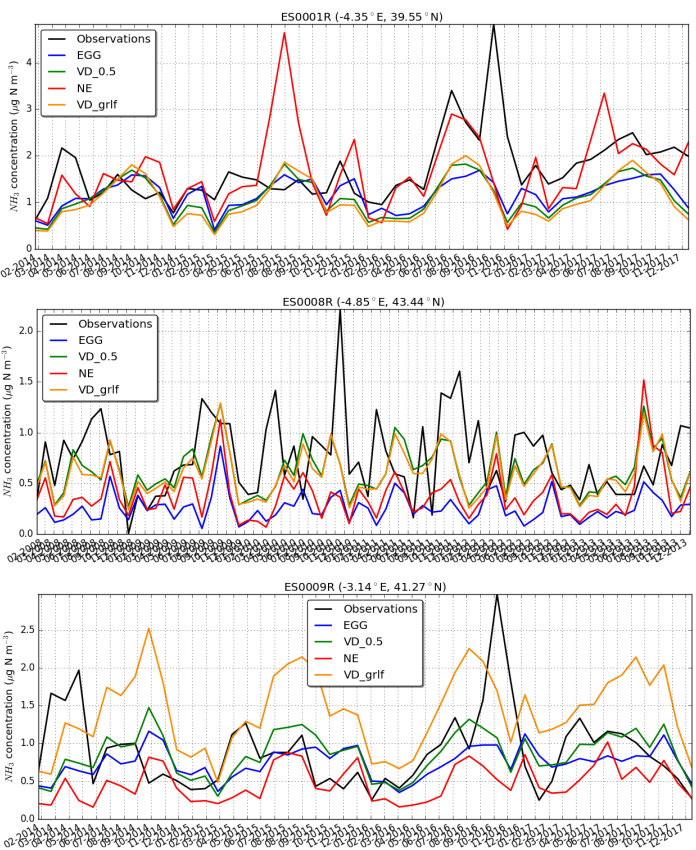

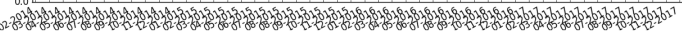
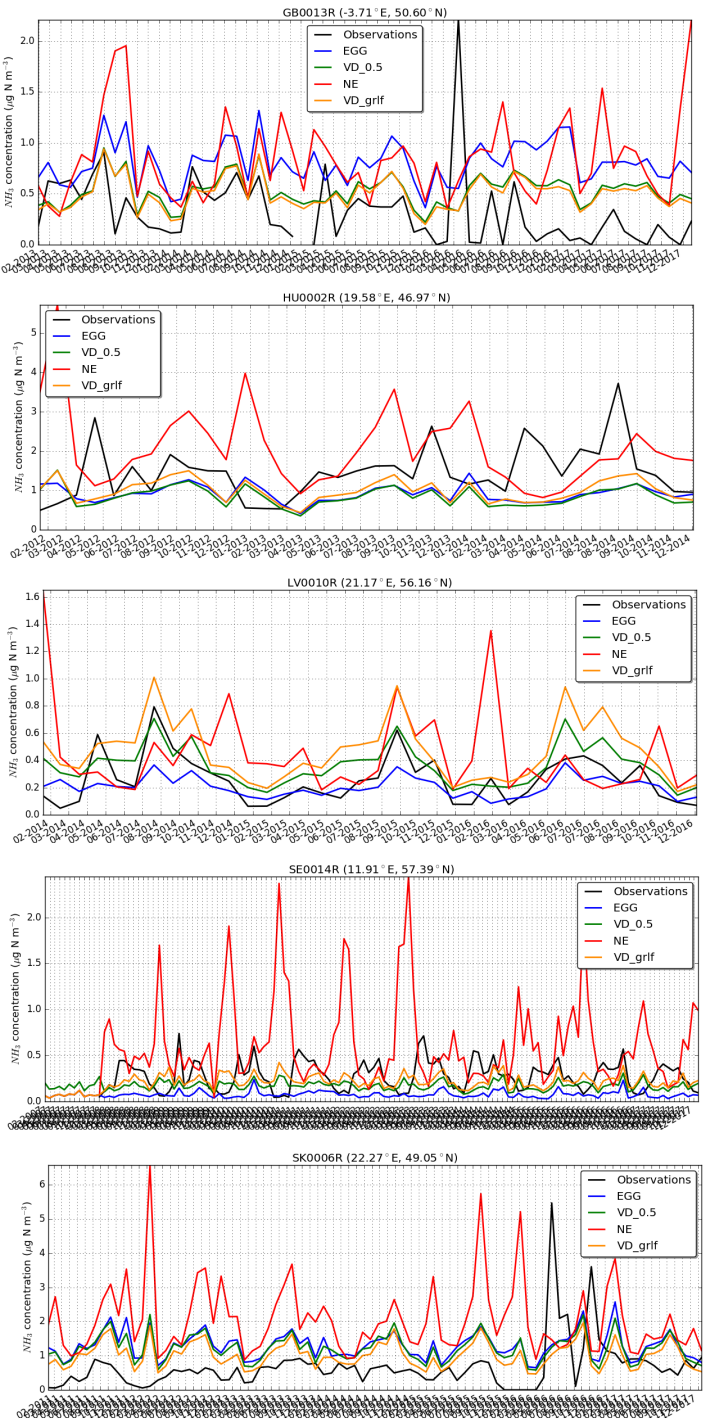

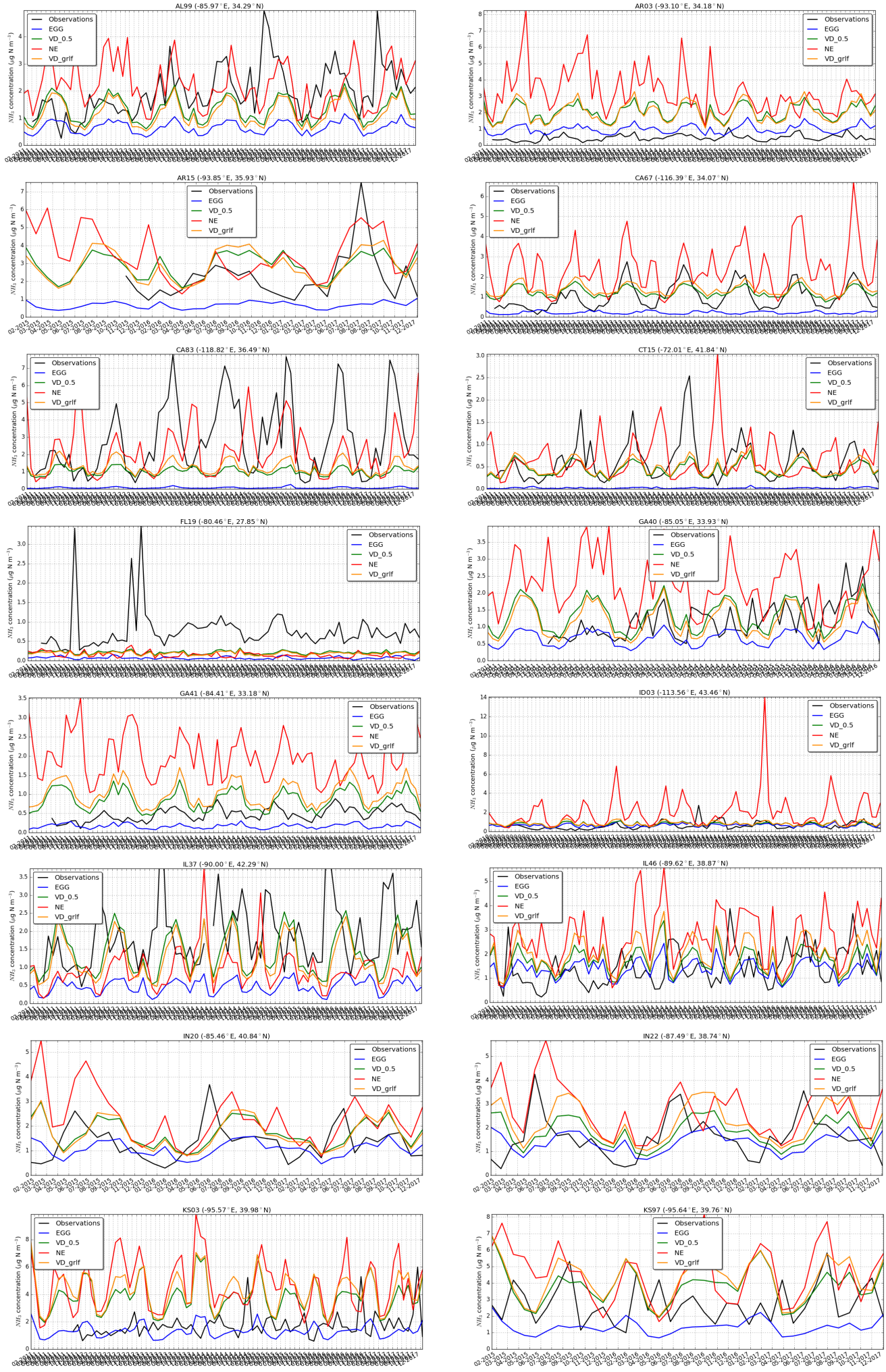

Fig. S8. Time-series of surface concentrations of ammonia in North American measurement sites (AMoN) for each of the simulations with different emissions. EGG stands for the simulation using traditional emissions from ECLIPSEv5, GFED4 and GEIA datasets, VD0.5 using Van Damme et al. (2018) satellite ammonia applying a constant lifetime for ammonia of 12 hours, NE using emissions presented in this paper (see section 2), and VDgrlf shows concentrations from the simulation using Van Damme et al. (2018)satellite ammonia applying a variable (modelled) lifetime. 

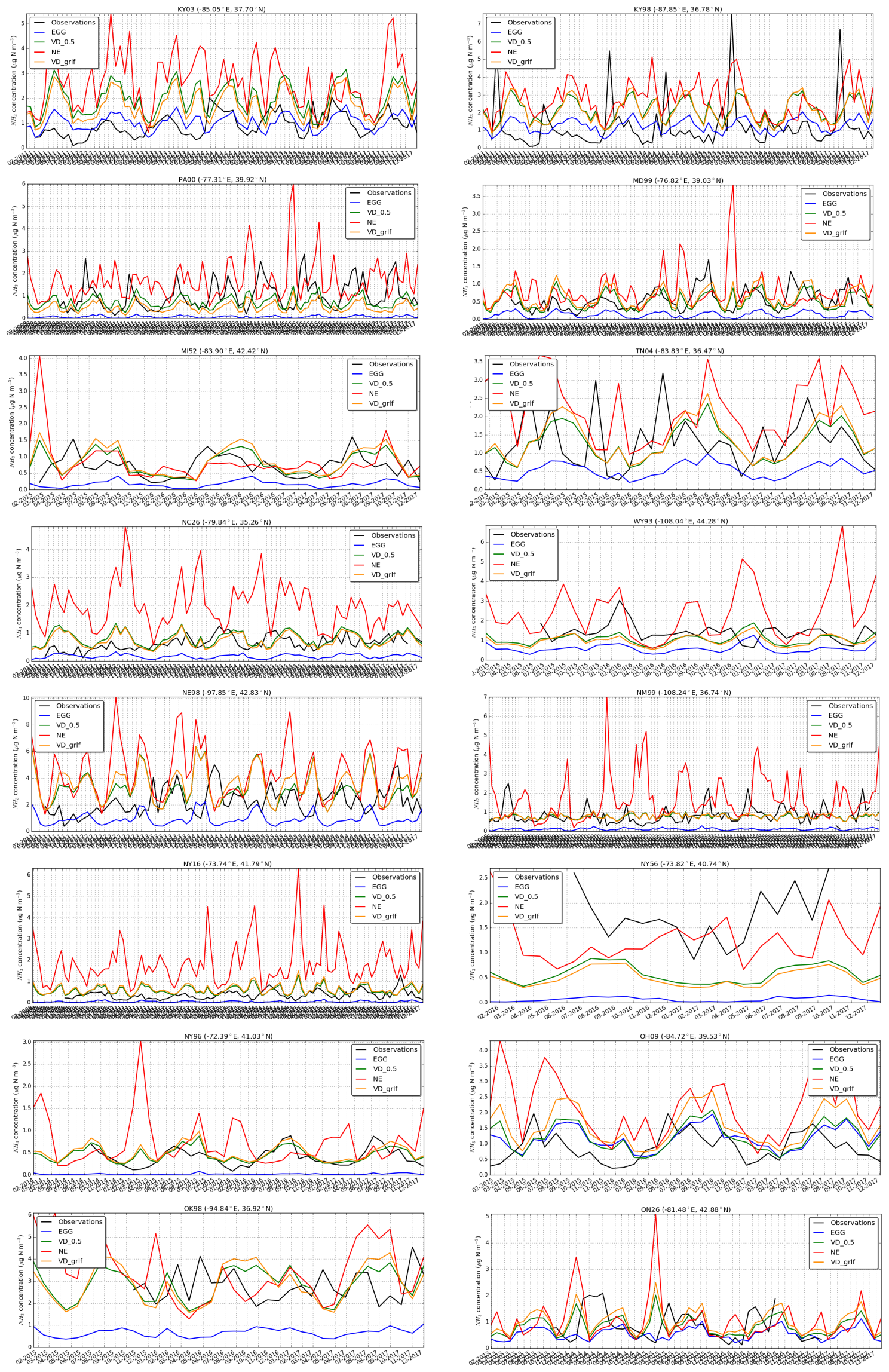

Fig. S8. Continued. 

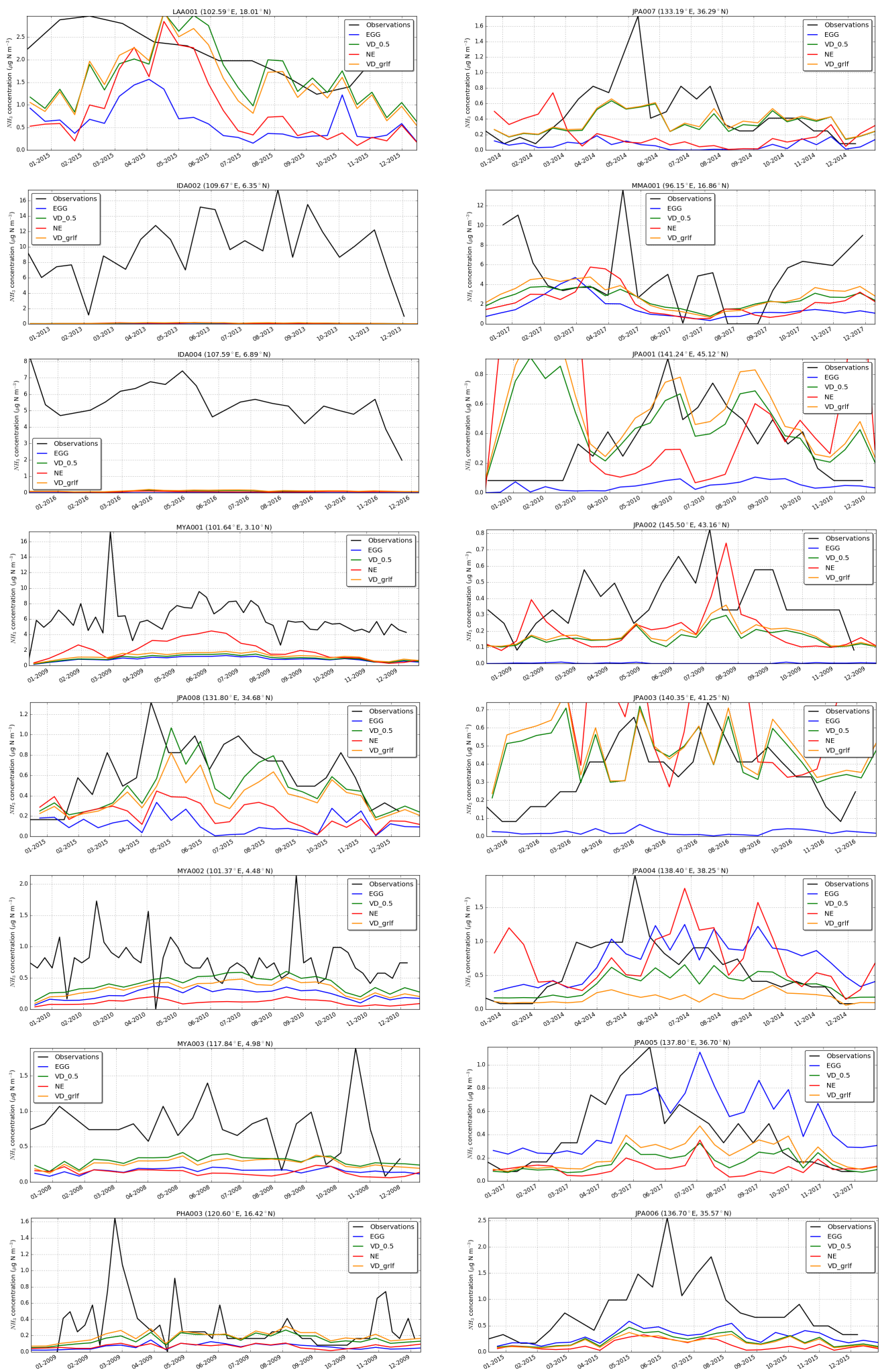

Fig. S9. Time-series of surface concentrations of ammonia in North American measurement sites (AMoN) for each of the simulations with different emissions. EGG stands for the simulation using traditional emissions from ECLIPSEv5, GFED4 and GEIA datasets, VD0.5 using Van Damme et al. (2018) satellite ammonia applying a constant lifetime for ammonia of 12 hours, NE using emissions presented in this paper (see section 2), and VDgrlf shows concentrations from the simulation using Van Damme et al. (2018) satellite ammonia applying a variable (modelled) lifetime. 

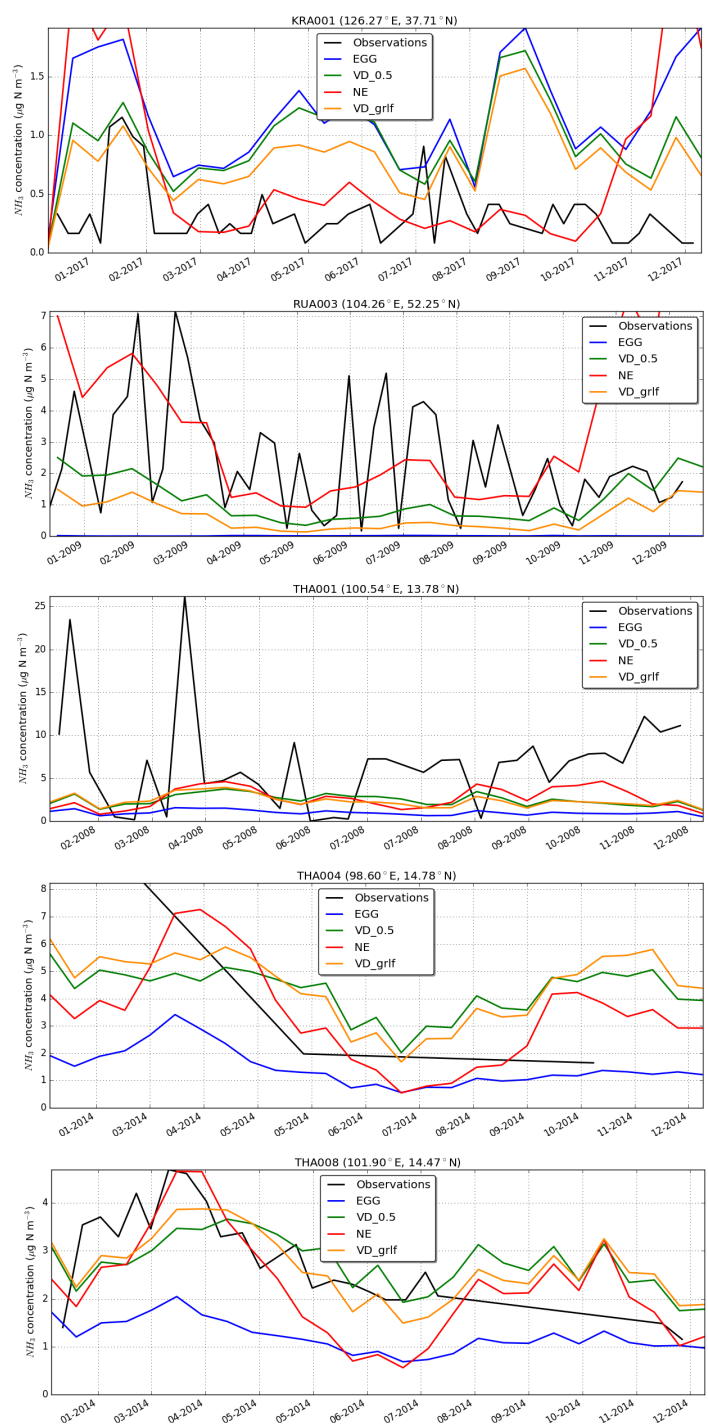

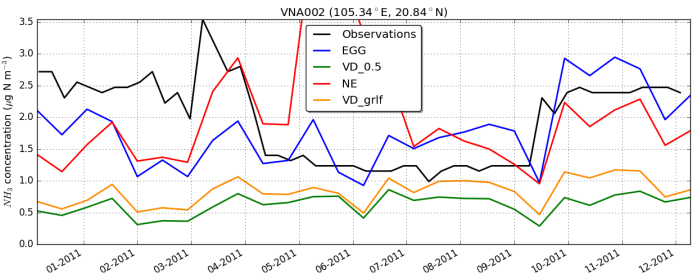
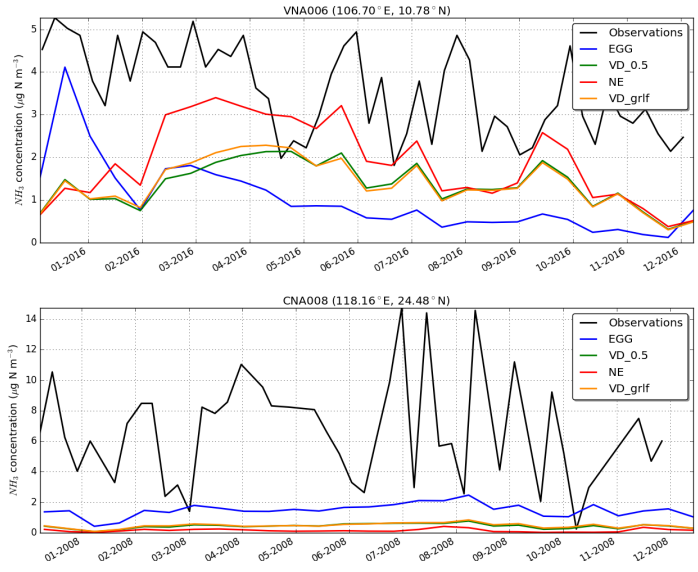
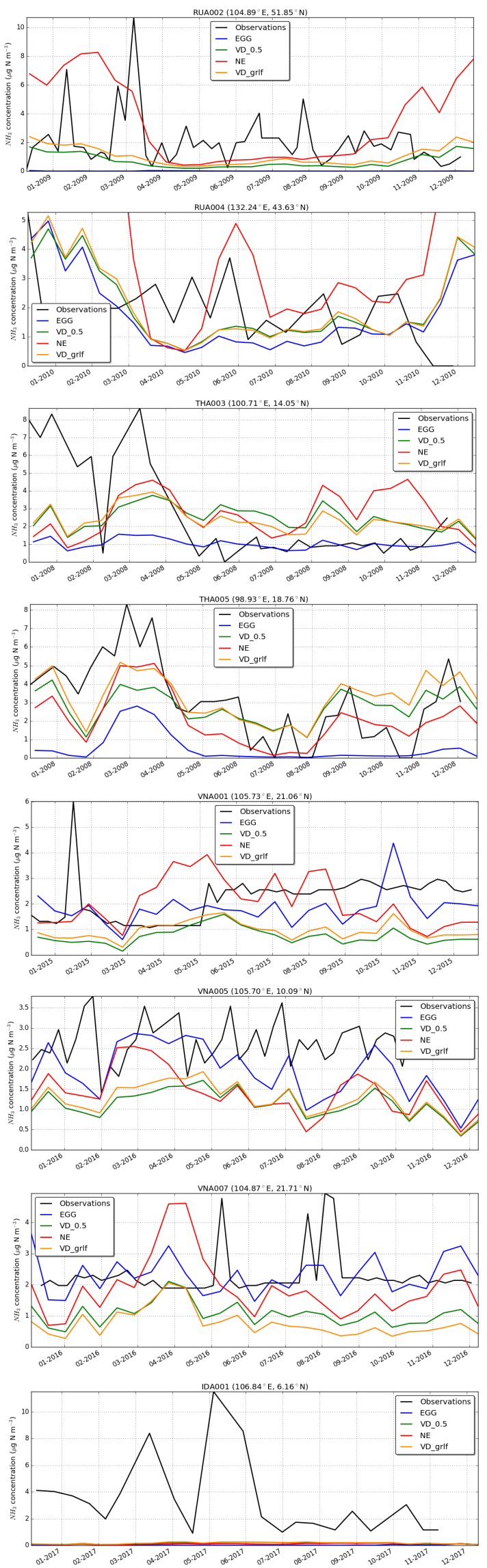

Fig. S9. Continued. 


\section{GLOBAL ANNUAL UNCERTAINTY OF $\mathrm{NH}_{3}$}
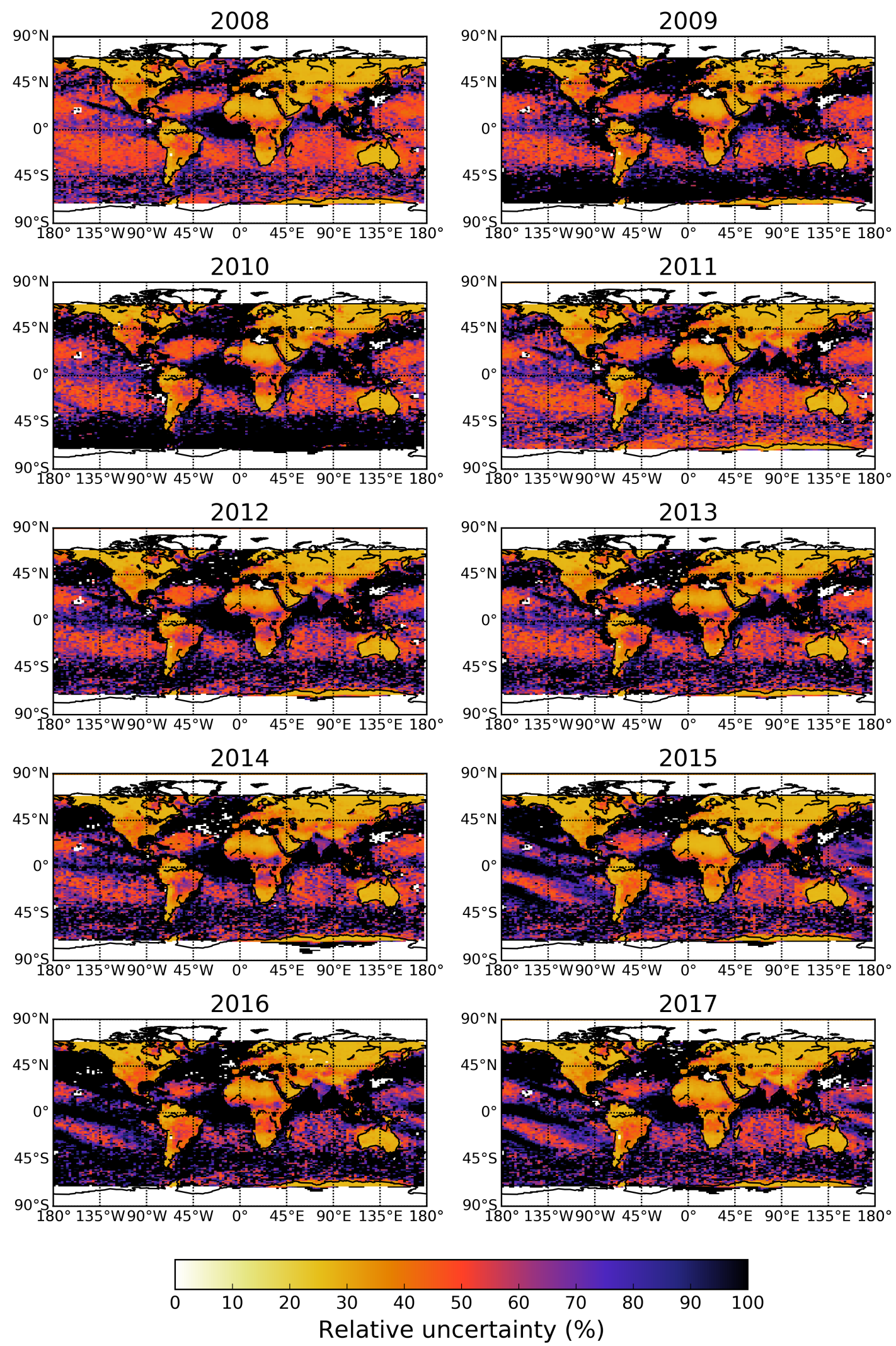

Fig. S10. Annual relative uncertainty of modelled surface concentrations expressed as the standard deviation of surface concentrations from a model ensemble (Table 1) divided by the average. 

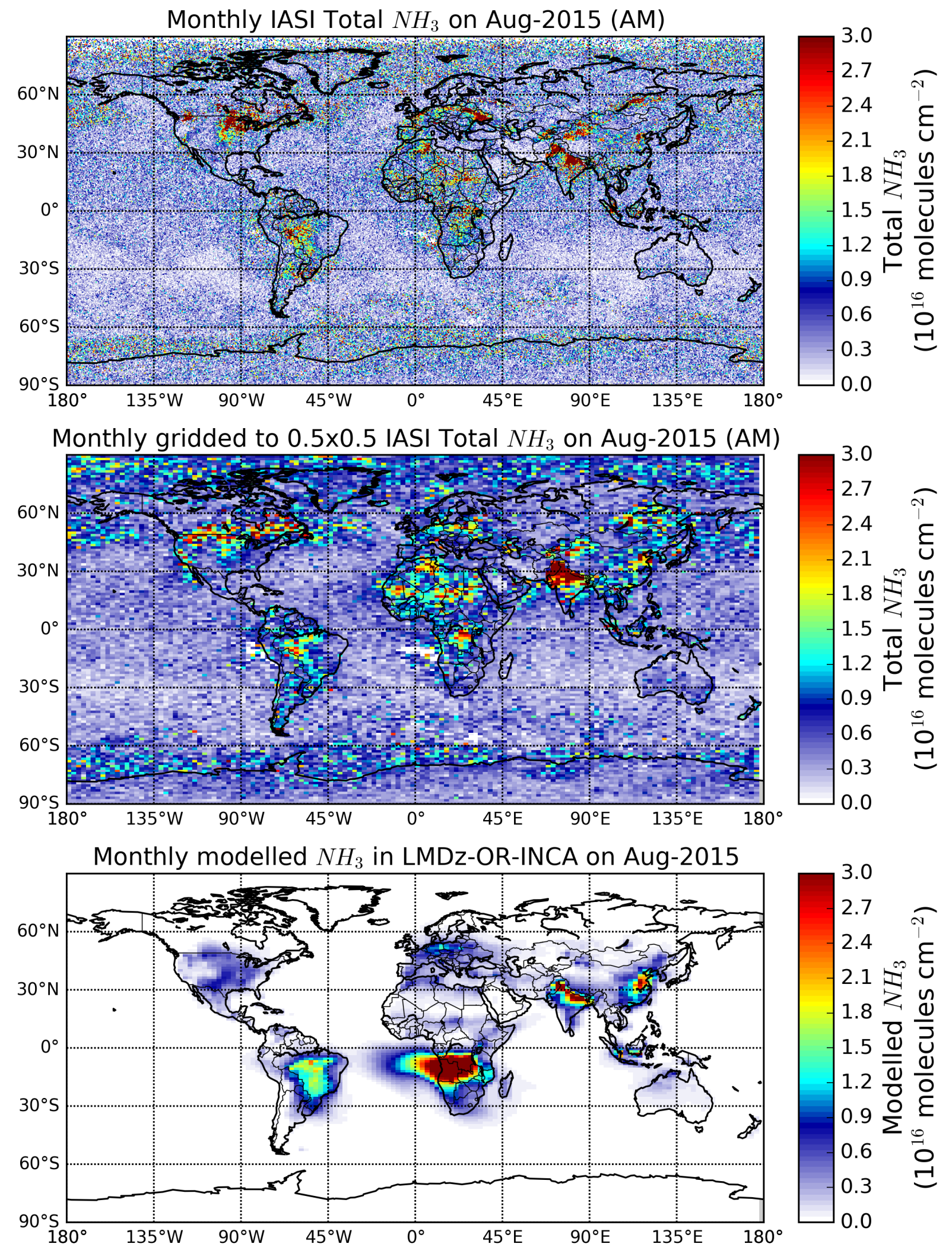

Fig. S11. An example of raw $(\mathrm{N}=19,735,468)$ satellite IASI column concentrations of ammonia (top panel) processed for the whole month (August 2015), gridded $2.5^{\circ} \times 1.3^{\circ}$ column concentrations (middle panel) resulted after IDW interpolation for the same month and modelled column monthly ammonia from LMDzORINCA (bottom panel) using the NE emissions. 